\title{
BMJ Open Exploring the effect of space and place on response to exercise therapy for knee and hip pain - a protocol for a double- blind randomised controlled clinical trial: the CONEX trial
}

\author{
Louise Fleng Sandal, ${ }^{1}$ Jonas Bloch Thorlund, ${ }^{1}$ Roger S Ulrich, ${ }^{2}$ \\ Paul A Dieppe, ${ }^{3}$ Ewa M Roos ${ }^{1}$
}

To cite: Sandal LF,

Thorlund JB, Ulrich RS, et al. Exploring the effect of space and place on response to exercise therapy for knee and hip pain-a protocol for a double-blind randomised controlled clinical trial: the CONEX trial. BMJ Open 2015;5:e007701.

doi:10.1136/bmjopen-2015007701

- Prepublication history for this paper is available online. To view these files please visit the journal online (http://dx.doi.org/10.1136/ bmjopen-2015-007701)

Received 16 January 2015 Revised 19 February 2015 Accepted 26 February 2015

\section{(a) CrossMark}

${ }^{1}$ Department of Sports Science and Clinical Biomechanics, University of Southern Denmark, Odense, Denmark

${ }^{2}$ Chalmers University of Technology, Gothenburg, Sweden

${ }^{3}$ University of Exeter, Medical School, Exeter, UK

Correspondence to Louise Fleng Sandal; Isandal@health.sdu.dk

\section{ABSTRACT}

Introduction: Context effects are described as effects of a given treatment, not directly caused by the treatment itself, but rather caused by the context in which treatment is delivered. Exercise is a recommended core treatment in clinical guidelines for musculoskeletal disorders. Although moderately effective overall, variation is seen in size of response to exercise across randomised controlled trial (RCT) studies. Part of this variation may be related to the fact that exercise interventions are performed in different physical environments, which may affect participants differently. The study aims to investigate the effect of exercising in a contextually enhanced physical environment for 8 weeks in people with knee or hip pain.

Methods and analysis: The study is a double-blind RCT. Eligible participants are 35 years or older with persisting knee and/or hip pain for 3 months. Participants are randomised to one of three groups: (1) exercise in a contextually enhanced environment, (2) exercise in a standard environment and (3) waiting list. The contextually enhanced environment is located in a newly built facility, has large windows providing abundant daylight and overlooks a recreational park. The standard environment is in a basement, has artificial lighting and is marked by years of use; that is, resembling many clinical environments. The primary outcome is the participant's global perceived effect rated on a seven-point Likert scale after 8 weeks exercise. Patient-reported and objective secondary outcomes are included.

Ethics and dissemination: The Regional Scientific Ethical Committee for Southern Denmark has approved the study. Study findings will be disseminated in peerreviewed publications and presented at national and international conferences.

Trial registration number: NCT02043613.

\section{INTRODUCTION}

The physical environment affects the persons in it and may potentially be of significance for health and treatment effects. Studies on

\section{Strengths and limitations of this study}

- The randomised controlled trial aims to investigate the effect of the physical environment on the effect of exercise therapy.

- The study focuses on the significance of the context in which treatment is delivered.

- The physical environment is a single component of the multifactorial concept of contextual effect, and isolating only one component may be difficult as interaction between several components may occur.

the role of physical environments conducted in hospital settings have reported that factors such as noise, daylight deprivation and light intensity may increase stress and pain level, reduce patient satisfaction and affect length of hospital stay. ${ }^{1-5}$ Many rehabilitation and hospital exercise facilities are today located in large rooms in basements or other windowless rooms with poor acoustics, not designed for optimal exercise therapy delivery. Such inexpedient physical environments may affect patients negatively and potentially result in a poorer result from the exercise or rehabilitation, if patients are feeling unwelcomed or are not motivated to comply with the exercise in the given environment. Theoretically, enhanced physical environments may create a positive atmosphere, enhance communication during exercise and potentially improve exercise performance, compliance and perceived well-being. Exercise is recommended as a lifelong treatment for chronic diseases such as cardiovascular diseases, diabetes and musculoskeletal disorders, including hip and knee osteoarthritis (OA) and joint pain. Despite the highlevel evidence that exercise provides on 
average moderate pain relief and functional improvement in patients with OA, large variation in effect is observed across studies and treatment effects may vary from small to large. ${ }^{6}{ }^{7}$ In addition to differences in characteristics of the exercise programmes studied, this may also relate to the fact that exercise interventions have been performed in different physical environments and that these environments may influence patients differently. ${ }^{8}$ It is plausible, but currently unknown, whether the physical environment can be modified in ways that enhance the effect of exercise therapy. To the best of our knowledge, this is the first trial to actively investigate if modification of the physical environment can be used in a positive way to enhance the effect from exercise therapy.

This study applies the term 'context effect' as a framework for elucidating how treatment effect is potentially caused by a complexity of factors in addition to the actual treatment effect. Context effects are defined as the effects of a given treatment, not directly caused by the treatment itself, but rather caused by the context or environment in which the treatment is given. ${ }^{8-11}$ Context effects may be considered as a parallel to placebo effects, which have been one of the most debated topics in modern medicine. ${ }^{12-15}$ Several authors have objected to the term placebo, as they argue that the definition is self-contradictory and inadequate. ${ }^{9}{ }^{16-19}$ Placebo is classically defined as giving an inert substance or treatment. ${ }^{10} 18$ However, if placebos are inert, they cannot have an effect, and if they have an effect, they cannot be inert. ${ }^{9} 101618$ Other terms have been suggested, such as non-specific effect, noncharacteristic effect, incidental effects, meaning response, placebo components and context effects, as applied in this study. ${ }^{9}{ }^{20-24}$ A clear distinction should be made between placebo effects and context effects. Placebo is associated with giving pills, injections or having surgery and often entails a form of deliberate deception, whereas context effects rather classify factors creating or enhancing a treatment effect. ${ }^{8-11}$ Factors contributing to context effects can be divided into different categories, such as characteristics of the patient and the practitioner, type of treatment, nature of disease and the physical environment. ${ }^{8}{ }^{11}$ This study will focus on the physical environment where exercise therapy is delivered, as it can be modified in a standardised and reproducible way to potentially enhance adherence and enhance the positive effects of exercise therapy.

The study aim is to investigate the effect of exercising in a contextually enhanced physical environment for 8 weeks in people with knee or hip pain. We hypothesise that participants exercising according to a standardised programme in a contextually enhanced physical environment will report greater improvement from exercise compared with participants following the same exercising programme in a standard physical environment as measured by patients' global perceived effect (GPE).
Further, we expect that the two exercise groups will be superior to a passive waiting list (WL).

\section{METHODS AND ANALYSIS}

\section{Study design}

This study is designed as a three-armed randomised controlled clinical trial. Participants are randomised to three intervention groups: exercise in a context enhanced physical environment $(\mathrm{EX}+\mathrm{ROOM})$, exercise in a standard physical environment (EX) or WL. Participants, investigators and exercise instructors are blinded to treatment allocation. The primary end point is the patient's GPE assessed after 8 weeks exercise on a seven-point Likert scale. Results from this study will be reported according to the CONSORT statement. ${ }^{25}$

\section{Participants}

Eligible participants are 35 years or older, self-reporting persisting knee and/or hip pain within the past 3 months and are willing and able to attend exercise therapy twice weekly at the University of Southern Denmark, Odense M. Exclusion criteria are: (1) comorbidities or contraindications prohibiting participation in exercise therapy; (2) inability to answer questionnaires or to speak, read or understand Danish; (3) already participating in exercise therapy, defined as an exercise programme supervised by a physiotherapist, or systematic training with a duration of 6 weeks or more started within 3 months to inclusion, aimed specifically at relieving knee or hip joint problems; (4) having had surgery to the hip/knee within the past 3 months or waiting for joint surgery in the coming 6 months. Participants are recruited via different pathways: posters and informational leaflets at general practitioners' offices, the orthopaedic department at Odense University Hospital or participant initiated contact through posters and articles in local newspapers, social media and word of mouth (figure 1). Participants are screened via telephone and, if eligible, they are invited to a baseline visit and written information is sent to the participants. At the baseline visit, the primary investigator gives oral information regarding the study and the participant signs the consent form if they are willing to participate. Baseline testing is performed directly hereafter.

\section{Intervention}

Participants are randomly assigned to one of three groups.

\section{Group EX+R00M: exercise in a contextually enhanced physical environment}

This exercise room is placed on the second floor in a newly built facility. It has a view to a newly reconstructed outdoor sport and recreational park. It has not been previously used in studies investigating exercise as a treatment option. 


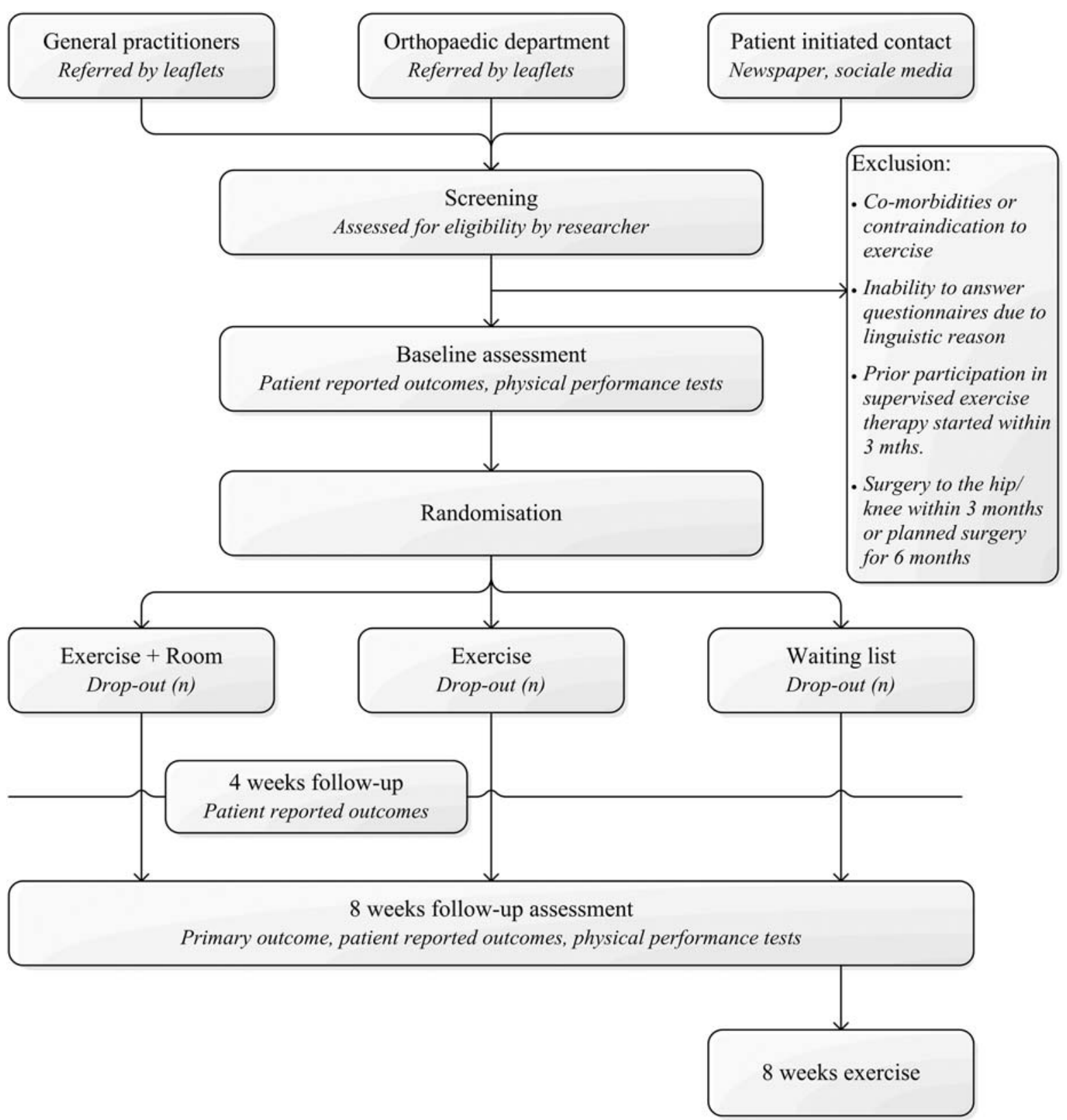

Figure 1 Flow chart, overview of the recruitment flow in the CONEX trial.

\section{Group EX: exercise in a standard physical environment}

This group will exercise in a room, which has been used in other exercise studies. The room is marked by years of use. It is placed in the basement and accessed through a series of staircases and hallways through the basement. This facility resembles many existing exercise facilities at hospitals and rehabilitation clinics and is considered a standard exercise environment.

\section{Contextual factors}

The physical environments are described and classified by a variety of contextual factors (table 1 ).

Acoustic properties such as speech interpretability, reverberation and background noise are measured by use of standard acoustic methods. ${ }^{26}$ Better acoustic properties, such as shorter reverberation time and higher speech interpretability, may reduce stress and improve communication. In hospital environments, high noise levels are associated with worse patient outcomes such as psychological stress and satisfaction with care. ${ }^{27}$ Background noise $(\mathrm{dB}(\mathrm{A}))$ is measured in empty rooms. Reverberation is measured as T20, the time interval for a $20 \mathrm{~dB}$ decay within a room. Reverberation is a measure of how long it takes for sound to decay in a room and a long reverberation time affects speech comprehension negatively. ${ }^{26}$ Reverberation and speech interpretability are descriptive of how well speech is perceived in a room. Speech interpretability is measured as speech clarity and transmission. Speech clarity is measured as Clarity Index within the initial $50 \mathrm{~ms}$ (C50); it compares 
Table 1 Descriptive environmental factors

\begin{tabular}{|c|c|c|c|}
\hline Dimension & Factor & $\begin{array}{l}\text { Contextually enhanced } \\
\text { physical environment }\end{array}$ & $\begin{array}{l}\text { Standard physical } \\
\text { environment }\end{array}$ \\
\hline \multirow[t]{12}{*}{ Indoor environment } & Light & & \\
\hline & Strength (Lux) & 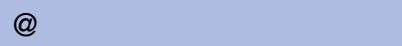 & $@$ \\
\hline & Source & Daylight + artificial light & Artificial light \\
\hline & Window/no window & Windows, floor to ceiling & No windows \\
\hline & Air quality & & \\
\hline & $\mathrm{CO}_{2}(\mathrm{ppm})$ & $@$ & $@$ \\
\hline & Temperature $\left({ }^{\circ} \mathrm{C}\right)$ & $@$ & $@$ \\
\hline & Humidity (\%) & $@$ & $@$ \\
\hline & Sound/noise & & \\
\hline & Background noise $(\mathrm{dB}(\mathrm{A}))$ & $@$ & $@$ \\
\hline & Speech clarity (C50, STI) & $@$ & $@$ \\
\hline & Reverberation (T20) & 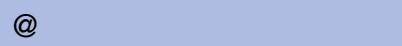 & $@$ \\
\hline \multirow[t]{2}{*}{ Décor } & Wall decorations & Picture of nature scenes & No decorations \\
\hline & View & $\begin{array}{l}\text { View of nature and outdoor } \\
\text { exercise environment }\end{array}$ & No view \\
\hline
\end{tabular}

early sound reflection with later sound reflection. Early sound reflections are positive for speech interpretability and later sound reflection will be perceived as noise. A high C50 indicates good speech interpretability. Speech Transmission Index (STI) is a measure of sound quality in transmission from sound source to receiver. Reverberation and speech interpretability are derived from tape recordings of loud clear noises emitted in the exercise rooms. Acoustic measures are obtained from two positions in the room with small, medium and large distance to the sound source. Light intensity is assessed using an adapted method from Walch et al. ${ }^{29}$ Light intensity is measured using a LUX meter (Amprobe, LM-100, light meter, Everett, Washington, USA) in two representative positions in the exercise rooms and additionally directly at windows, if present in the room. Three consecutive measures are obtained from each position and averaged. Light measurements are taken as close to the exercise time as possible. Daylight and brighter rooms are associated with lower pain perception and lower postoperative analgesic intake in hospital environments. ${ }^{28} 29$ Air quality is described by $\mathrm{CO}_{2}$ concentration, temperature and air humidity in the exercise rooms during exercise. It is assessed with an air quality data logger, set to collect data at $30 \mathrm{~s}$ intervals (Trotec, BZ-30, data logger, Heinsberg, Germany). Furthermore, carefully selected pictures of nature scenes are hung in a contextually enhanced physical environment. Viewing nature pictures or visual stimuli of nature elements has been known to reduce stress in an office setting and influence recovery time and decrease pain in patients following surgery. ${ }^{15} 30-33$

\section{Exercise}

The exercise programme for participants in the EX + ROOM and EX group is based on the standardised
NEuroMuscular EXercise (NEMEX) programme. It is described in detail elsewhere ${ }^{34}$ and has previously been investigated for feasibility in patients with severe knee or hip OA. ${ }^{34}$ The NEMEX programme is based on biomechanical and neuromuscular principles, which aim to improve sensorimotor control and achieve functional stability. ${ }^{34}$ The NEMEX programme has previously been shown to be effective in relieving pain and improving function in populations with knee or hip pain such as anterior cruciate ligament injuries, ${ }^{35-38}$ meniscectomised participants, ${ }^{39}{ }^{40}$ and patients with hip or knee OA undergoing total joint arthroplasty. ${ }^{34}{ }^{41}$ Exercise is performed as a group exercise, and all exercise sessions are supervised. All instructors will be certified in the NEMEX programme. To ensure consistency between instructors, they will participate in a 2-day course, Good Life with OA in Denmark, focusing on lower limb OA management and neuromuscular exercise. After completing the course, all instructors will go through the exercise programme with the primary investigator to ensure consistency in instructing and supervising exercise as well as going through how volume, load and progression of exercise and pre-exercise and postexercise pain should be documented in participants' exercise dairies. The $\mathrm{EX}+\mathrm{ROOM}$ and $\mathrm{EX}$ group will exercise on the same weekdays, twice a week for 1 hour duration. An instructor will first supervise the EX+ROOM group and then the EX group. Consequently, all of the instructors will have supervised the NEMEX programme in both physical environments and for the same amount of time, that is, if an instructor supervises the EX+ROOM group, then they will supervise the EX group as well. This is done to ensure consistency in delivery instructions and supervision of exercise across study participants and to ensure that any 
effect that a given instructor may have on the exercise and participants should be similar between physical environments.

\section{Group WL: WL/control group}

Participants randomised to a WL are placed on a passive WL for a period of 8 weeks, and thereafter offered 8 weeks of structured resistance exercise. These participants act as an observational group and represent the natural course of disease in participants with knee and/ or hip pain. After the 8 weeks when follow-up data for the current study have been collected, the participants are offered resistance exercise rather than neuromuscular exercise for logistic reasons, such as avoiding taking up place in the designated exercise rooms used in the study and consequently affecting the time to completion of the study.

\section{Primary outcome}

Participants' GPE assessed at 8 weeks will be the primary end point of the trial. Participants are asked to respond to the following question: Compared to before you entered the study, how are your knee/hip problems now? on a seven-point
Likert scale. The GPE scale ranges from 'markedly worse' through 'no change' to 'markedly improved'. GPE is a reliable method for measuring the effect of clinical interventions. ${ }^{42}{ }^{43}$ It has previously been used in studies investigating contextual effect of treatment. ${ }^{44}$ The validity of GPE scales has been questioned. However, a study on the correlation between transition ratings and prescore and postscore of quality of life questionnaires showed a correlation of 0.8 between the change score of the questionnaire and the transition ratings suggesting that transition scales, such as GPEs, are valid for detecting changes and can be used in clinical trials as primary outcome measures. ${ }^{43}$

\section{Secondary outcomes}

All outcomes and time points for data collection are listed in table 2.

\section{Patient-reported outcomes}

Participants answer the Danish versions of the Knee injury and Osteoarthritis Outcome Score (KOOS) or the Hip disability and Osteoarthritis Outcome Score (HOOS) depending on either knee or hip problem

\begin{tabular}{|c|c|c|c|}
\hline Variable & Baseline & 4 weeks & 8 weeks \\
\hline \multicolumn{4}{|l|}{ Baseline data } \\
\hline Height $(\mathrm{cm})$ & @ & NA & $@$ \\
\hline Weight (kg) & $@$ & NA & $@$ \\
\hline Age (years) & $@$ & NA & NA \\
\hline Gender (F/M) & $@$ & NA & NA \\
\hline Marital status & $@$ & NA & NA \\
\hline Educational level & $@$ & NA & NA \\
\hline Employment status & @ & NA & NA \\
\hline Alcohol consumption & $@$ & NA & NA \\
\hline Smoking & @ & NA & NA \\
\hline Physical activity level at work and leisure & $@$ & NA & NA \\
\hline \multicolumn{4}{|l|}{ Primary outcome } \\
\hline Global perceived effect (7-point Likert scale) & NA & $@$ & $@$ \\
\hline \multicolumn{4}{|l|}{ Secondary outcomes } \\
\hline \multicolumn{4}{|l|}{ Patient-reported outcomes } \\
\hline Knee/Hip Injury and Osteoarthritis Outcome Score & $@$ & $@$ & $@$ \\
\hline Short-form 36 Health Survey & $@$ & $@$ & $@$ \\
\hline Modified Arthritis Self-Efficacy Scale & $@$ & $@$ & $@$ \\
\hline Patient Acceptable Symptom State $(y / n)$ & NA & NA & $@$ \\
\hline Patient satisfaction (5-point Likert scales) & NA & NA & $@$ \\
\hline Stress (100 mm VAS) & @ & NA & $@$ \\
\hline \multicolumn{4}{|l|}{ Objective physical function tests } \\
\hline Aerobic capacity $(\mathrm{ml} \mathrm{O} / \mathrm{min} / \mathrm{kg})$ & @ & NA & @ \\
\hline Isometric strength hip abduction (Nm) & $@$ & NA & $@$ \\
\hline Isometric strength knee extension $(\mathrm{Nm})$ & $@$ & NA & $@$ \\
\hline Single-limb mini squat & @ & NA & $@$ \\
\hline Knee bends/30 s (n) & @ & NA & @ \\
\hline Chair stands/30 s (n) & @ & NA & $@$ \\
\hline Walking test, $40 \mathrm{~m}$ fast paced (s) & $@$ & NA & @ \\
\hline One leg hop of distance $(\mathrm{cm})$ & @ & NA & $@$ \\
\hline
\end{tabular}


being the primary cause of pain. The KOOS and HOOS are joint-specific questionnaires, developed to assess participants' opinion about their knee or hip problems. ${ }^{45} 46$ They consist of five subscales: pain, symptoms, activities of daily life function, sport and recreational function, and joint-related quality of life. ${ }^{47}$ Each subscale consists of a set of items specific to the subscale and each item is assessed via a Likert scale with five possible answer options ranging from 0 (no problems) to 4 (extreme problems). The Likert score is transformed into a $0-100$ scale with 0 representing extreme knee problems and 100 representing no knee problems. ${ }^{45}$ The KOOS and HOOS have good psychometric properties for patient groups with knee injury, knee replacement, hip dysfunction and hip replacement. ${ }^{46-50}$

The Medical Outcome Study 36-item short form general health survey (SF-36) is a generic patientreported health status measure. ${ }^{51-53}$ It consists of 36 items organised under eight subscales: (1) physical functioning, (2) role limitations because of physical health, (3) bodily pain, (4) social functioning, (5) general mental health, (6) role limitations because of emotional problems, (7) vitality and (8) general health perception. ${ }^{53}$ Low scores indicate limitations in activities and a perception of poor health, while high scores indicate no limitations and good health. ${ }^{53}$ Validity and reliability of the SF-36 is adequate and the questionnaire is widely used. $^{51} 52$

A modified measure of self-efficacy is included to evaluate patients' perception of functionality or limitations to their functionality caused by their knee or hip problem. Self-efficacy is defined by Bandura ${ }^{54}$ as "belief in one's capability to organise and execute the course of action required to produce given attainments". Self-efficacy is assessed with a modified version of the Arthritis Self-Efficacy Scale (ASES) ${ }^{55}$ previously used in a similar patient group. ${ }^{56}$ The modified version of ASES consists of 11 single items from the two subscales, pain and other symptoms. Participants rate their ability to cope with pain and symptoms related to their joint problem on a 10-100 scale, with 10 indicating very uncertain and 100 indicating very certain with 10-point increments. ${ }^{57}$

A series of single-item questions are included. The Patient Acceptable Symptom State is assessed by asking a single yes/no question: "Considering your knee function, do you feel that your current state as satisfactory? With knee function you should take into account all the activities you have during your daily life, your level of pain and other symptoms and your quality of life. ${ }^{58}$ If participants rate their current symptom state as unacceptable, a follow-up question is asked as to whether they consider the treatment to have failed. Further, participants are asked to answer five GPE questions specific for each of the five subscales of either the KOOS or HOOS, rating either improvement or deterioration and finally an indication of whether these changes are perceived as important or unimportant by the participants. These single items are included in order to assess minimal clinical important changes for the five subscales of the KOOS and HOOS. Stress is estimated as 'general stress level' measured on a $100 \mathrm{~mm}$ visual analogue scale ranging from no stress to stress as severe as could be. ${ }^{59}$

Patient-reported outcomes are collected using an online survey. At baseline and 8 weeks follow-up, participants answer the survey on a computer in the examination room without the investigator being present. At 4-week follow-up, an email is sent to participants, who answer at home. To ensure high data completion, an email reminder is sent if no reply is received within 35 days. Further, participants are called by phone if there is no reply to the reminder email.

\section{Functional performance}

Patients' aerobic capacity is estimated during a submaximal work rate bicycle test. ${ }^{60}$ Patients pedal until they reach a steady state, with a stable pulse rate ranging between 120 and $170 \mathrm{bpm}$, normally within $6-7 \mathrm{~min} .{ }^{60}$ Participants' aerobic capacity is estimated from work rate and stabile pulse rate by the use of Åstrand's Nomogram. ${ }^{60}$

Maximal isometric knee extension and hip abduction strength will be tested using dynamometry (JTECH medical, Commander Echo, Salt Lake City, Utah, USA). A suction cup is mounted on a door behind the examination couch. A strain gauge, measuring pull in Newton, is placed in between the suction cup and a fixation belt strapped around the participant's ankle above the lateral malleoli. For knee extension, participants sit on an examination couch with a hip angle of $90^{\circ}$ and a knee angle of $90^{\circ}$. Participants are asked to press against their foot the belt in a forward motion. The distance from the knee joint axis to the middle of the fixation belt is measured. Consequently, isometric muscle strength is measured as torque. For hip abduction, participants lie on the couch with the tested leg straight and are asked to press the lateral malleoli against the belt. The distance from the trochanter major on the femoral bone to the middle of the fixation belt is measured. One practice trial is allowed and thereafter three maximal contractions are performed separated by a $60 \mathrm{~s}$ pause. Isometric muscle strength is normalised to body weight to increase comparability. The methods for assessing isometric muscle strength have been adapted from Thorborg et $a b^{61}$ who reported good intertester reliability with an interclass correlation coefficient ranging from 0.76 to 0.95 and SE of measurement between $5.0 \%$ and $10.4 \%$ for hip and knee strength assessments.

Physical function is assessed by five performance tests: (1) single limb mini squats, ${ }^{62}$ (2) number of knee bendings on one leg during 30 s standing, ${ }^{63} 64$ (3) number of chair stands during $30 \mathrm{~s},{ }^{66}$ (4) $40 \mathrm{~m}$ fast-paced walking test $^{65}$ and (5) one leg hop for distance. ${ }^{63}$ All performance tests have been found valid to assess lower extremity function in different patient groups with knee or hip 
problems. ${ }^{63}$ 66-68 As large variation regarding age and function within participants of this trial is expected, a test battery with a wide range of difficulty of the performance tests is therefore chosen to ensure that all participants would be challenged. A floor effect may be evident in the one leg hop for distance test as some participants may not be able to hop at all. No ceiling effects are expected for any of the functional performance measures.

\section{Explanatory outcomes and nested qualitative study}

To investigate how the physical environment and other potential context factors, such as participant and practitioner interaction and behaviour, may interact and mediate the treatment effects, explanatory outcomes are included. Explanatory outcomes have been selected to explain the process by which context effects work and possibly elucidate which elements within the physical environment enhance treatment effects and how these elements affect the patients and practitioners. A qualitative study will be embedded within the randomised controlled trial (RCT) design. The aim of the qualitative study is to investigate how the participants experience the two different physical environments. Observation is performed in both rooms during exercise sessions to describe and identify behaviour of practitioners and participants specific to the different physical environments. Focus group interviews will be conducted with participants to investigate their experiences with the exercise environments and to invite participants to articulate and elaborate on their thoughts on how the physical environment has affected them. Three focus group interviews will be conducted with a total of 10-20 participants from the contextually enhanced physical environment and three focus group interviews with a similar number of participants from the standard physical environment, that is, six focus groups in total. Participants invited to the focus groups will be those randomised to exercise in the RCT design (group EX+ROOM and group EX). The interviews will be transcribed and analysed using thematic coding comparing within and across the different physical environments. Additionally, in-depth individual interviews will be performed with six participants. To ensure the blinding of participants throughout the study, all interviews will be conducted after the intervention and after follow-up testing has been completed.

Additionally, a patient-reported outcome 'participant satisfaction' is reported as participants' satisfaction with the exercise intervention in itself as well as satisfaction with specific contextual factors within the physical environment. Eleven single items scoring the different factors of the physical environment, such as lighting, cleanliness, access, decoration, etc, are administered to participants in intervention groups EX+ROOM and EX. The items are adapted from Tsai et al. ${ }^{69}$ Satisfaction is scored on a five-point Likert scale ranging from 1 to 5 ( $1=$ strongly dissatisfied, 2=dissatisfied, 3=fair, 4=satisfied and $5=$ strongly satisfied).

\section{Compliance and adverse events}

In the two exercise groups, compliance is considered good at $75 \%$ or if 12 of 16 possible exercise sessions are attended. Participants in the WL group are asked at 8 weeks follow-up whether they have started any exercise courses within the past 8 weeks. If answering yes, they are asked to describe the change. This is done in order to account for compliance to the WL design. Self-reported adverse events occurring in between exercise sessions are recorded at 4 and 8 weeks in the online survey. Adverse events are defined as any events that the participants found were restricting them physically, mentally or socially. Participants also indicate whether they have been in contact with either their general practitioner or the hospital in relation to their adverse event. Any adverse events occurring during the exercise sessions are recorded by the supervising instructors.

\section{Randomisation}

Randomisation is performed immediately after baseline assessment and is administered by a research coordinator not otherwise involved in the study. Patients are consecutively assigned and given a numbered, sealed opaque envelope entailing treatment allocation. The randomisation sequence is computer-generated and prepared by a statistician with no clinical involvement in conducting the trial. To avoid imbalances in treatment allocation among people with knee and hip pain, two block randomisation lists were computer-generated (with a 2:2:1 allocation). The block size is kept secret to maintain blinding; each block consisted of either 5 or 10 patients. The randomisation lists and envelopes are kept in a secure location at the university.

\section{Blinding procedure}

Participants are blinded to the study aim in order to avoid excess focus on the physical environment, which potentially could exaggerate context effects from the physical environment. Participants are therefore informed that they are participating in a study evaluating the effects from exercise compared with being on a WL and are not aware that the true aim of the study is to investigate the possible additional effect from an enhanced physical environment on exercise. The instructors supervising the exercise sessions are also not informed about the true aim of the study. However, they are aware that exercise sessions are performed in different rooms as they supervise sessions in both rooms. The instructors have been informed that the different exercise rooms are used for practical and logistic reasons. The primary investigator conducting baseline and follow-up testing is also blinded to treatment allocation, and participants are instructed to not to speak about the intervention with the investigator, thereby keeping blinding intact.

Sample size estimation and power considerations This study is designed as a superiority trial with three groups $(\mathrm{EX}+\mathrm{ROOM}, \mathrm{EX}$ and $\mathrm{WL})$. Since this is the first 
study to investigate the additional effect of an enhanced physical environment on the effect of exercise therapy as treatment for knee or hip pain, there are no previous data on which to base our sample size estimation. Thus, the power calculation is based on factors such as feasibility, that is, how many participants will be realistic to include with the recruitment period and pragmatic issues such as availability and capacity of the different exercise rooms. Taking these aspects into consideration, 100 participants will be included in the trial. To be able to account for the natural disease progression or regression towards the mean, the $\mathrm{WL}$ is included in the design. A randomisation with a 2:2:1 allocation is chosen, and thus 40 participants are randomised to the EX+ROOM and EX groups, respectively, and 20 participants are randomised to the WL group. We anticipate that individuals in the WL group will experience limited effect. With 40 participants in each of the two exercise groups $(\mathrm{EX}+\mathrm{ROOM}$ and $\mathrm{EX})$, we are able to detect a difference of 0.75 on the GPE scale ranging from -3 to 3 with a SD of 1.2, a p value of 0.05 and a power of $80 \%$.

\section{Statistical evaluation}

All three intervention groups (EX+ROOM, EX and WL) will be examined for comparability at baseline with respect to demographic factors using analysis of variance (ANOVA) and $\chi^{2}$ test as appropriate.

The primary analysis on the GPE data will be conducted with a Student unpaired t test comparing the EX + ROOM intervention group with the EX intervention group at the 8-week follow-up. The Bonnet-Price median test will be conducted if assumption of normality in the GPE data is not supported. The WL intervention group is considered a reference group describing the natural progression of disease for the included study population and is not included in the primary analysis. However, to check the general assumption that exercise is more effective than no intervention, an unpaired t test is conducted to compare the exercise groups with the WL.

The secondary outcomes, the KOOS/HOOS, SF-36, ASES and physical function outcomes, are analysed as repeated measures (ie, change from baseline over 4 and 8 weeks follow-up for patient-reported outcomes and baseline to 8-week follow-up for physical function tests) applying a mixed linear effects model with 'participant' as the random effect and sex, age and joint as fixed effects. As for the primary outcome, only the EX+ROOM and EX groups are compared. Additionally, to test an a priori hypothesis of a graded relationship between groups EX $+\mathrm{ROOM}>\mathrm{EX}>\mathrm{WL}$, a linear test for trend will be conducted as an explanatory analysis on all outcomes. A $\chi^{2}$ test for trend is applied for dichotomous outcomes and a linear test for trend is applied for continuous outcomes. Pairwise comparison of groups will be conducted if the trend test was significant, to describe the association between group and outcome, that is, $\mathrm{EX}+\mathrm{ROOM}$ versus $\mathrm{EX}$ and $\mathrm{EX}$ versus WL. For dichotomised outcomes, a $\chi^{2}$ test is applied, and for continuous outcomes ANOVA is applied.
Intention-to-treat analysis is performed and the last observation is carried forward for missing data at follow-up for secondary outcomes. The primary outcome is a transition score, which is not assessed as baseline. For any participants lost to follow-up, GPE data will be missing. Further, a per-protocol analysis is conducted including only those with good compliance with the exercise intervention (participated in at least 12 of 16 sessions) in the EX+ROOM and EX groups, respectively.

A detailed statistical analysis plan will be drafted and approved by all authors before being made publicly available prior to breaking the randomisation code and conducting data analysis. To further minimise the risk for bias introduced during analysis and interpretation, data analysis will be performed by a third party not otherwise related to the study. Intervention groups will be allocated with arbitrary names. Interpretation will be performed by the primary investigator in collaboration with the research team prior to revealing treatment allocation, thereby interpreting the results blindly. ${ }^{70}$ Consequently, two interpretation scenarios will be drafted on the basis of the primary outcome data, that is, comparing treatment $\mathrm{A}$ with treatment $\mathrm{B}$, one assuming that group $\mathrm{A}$ will be the $\mathrm{EX}+\mathrm{ROOM}$ group and the other assuming that A will be the EX group.

\section{ETHICS AND DISSEMINATION}

The findings of this study will be disseminated though peer-reviewed publications and through international conference presentations.

The primary ethical concern in this study is that the true aim of the study is withheld from participants. Withholding the aim disables participants from considering the implications of the research and from assessing whether or not they want to contribute to the investigation of this aim. However, blinding the true aim is imperative to the study design as an effect from the physical environment may be overestimated or underestimated if participants are explicitly made aware of the actual aim of the study. Participants are therefore told that the study is designed to investigate the effect of neuromuscular exercise as an early treatment strategy for musculoskeletal pain. Similarly, the supervising instructors are also blinded to the true aim of the study. The instructors are aware that the exercise is performed in different environments, but they are told this due to logistic reasons. The ethics committee has been explicitly made aware that study participants and instructors are not made aware of the true study aim and despite this sanctioned the study without any reservations or conditions.

\section{DISCUSSION}

Context effects may constitute an important part of the effects of exercise therapy. Investigating context effects will provide knowledge on how the physical environment 
may be exploited to enhance the effects of exercise therapy in addition to the effect of the specific exercise. Exercise is an effective and widely used core treatment strategy for chronic diseases, such as musculoskeletal disorders, cardiovascular disease and diabetes. Adding to the effect of exercise through context effects from a contextually enhanced physical environment in exercise facilities may be highly beneficial for patients across a number of diseases.

Previous research in context effects from physical environments has been conducted in hospital settings. ${ }^{27}$ A comprehensive review from 2008 showed that certain elements within a hospital context, such as noise and lighting level, have an impact on the number of medical errors as well as increased pain and stress levels for patients and staff. ${ }^{27}$ Research in other healthcare settings has been sparse. During an initial literature review, only one study was identified as having investigated physical therapy and its relation to the physical environment. The literature review comprised groups of search terms for context effects, exercise/physical therapy and terms for physical environments. Articles were searched for in MEDLINE, Scopus and single-specific journals such as the Health Environment Research and Design journal. When reviewed, this single study used observation, surveys and interviews to learn more about the design of a hospital rooftop garden rather than investigating if the physical environment had an additional effect on the physical therapy. $^{71}$ Further, the therapy of the study was described as activities including gardening, golf putting and events such as concerts or barbeques, not regular exercise. Consequently, this is, to the best of our knowledge, the first study to investigate if there is an effect from an enhanced physical environment in addition to exercise when compared with exercise performed in a standard setting.

The three-armed RCT design of the present study has several advantages. It has been widely discussed whether the placebo effect can be explained by spontaneous remission or regression towards the mean. ${ }^{15}{ }^{72-74}$ To rule out either of these as explanatory factors of a possible effect, the WL group is included in the design as an untreated reference group. The WL group illustrates the natural course of disease for the study population during the study period. Consequently, if a difference is seen between the two exercise rooms, the WL group enables an assessment of whether the difference is caused by spontaneous remission by comparing the exercise groups to the WL. To optimise the number of study participants, a 2:2:1 allocation with half the number of participants allocated to the WL is chosen. The three-armed design also allows for a test for trend across groups. This form of analysis has been previously applied in a study investigating context effects originating from patient and practitioner interaction. ${ }^{44}$

Context effects are a multifactorial concept and several factors, other than the physical environment, may contribute to the context effect of a given treatment. Literature reviews on context effects have additionally suggested factors, such as characteristics of patients/participants, practitioner/instructors or treatment and nature of disease, as potentially contributing to the total context effect, and theoretically components may interact and possibly have synergistic effects. ${ }^{8} 9162475$ Especially the interaction between patient and practitioner has been suggested as a significant contributor to context effects. ${ }^{44-85}$ In a recent study, Kaptchuk et $a l^{44}$ found that patients with irritable bowel syndrome, who were treated by a warmer and friendlier practitioner, had significantly better results from sham acupuncture than those treated by a practitioner, who limited eye contact and avoided conversation. Similarly, Suarez-Almazor et $a l^{83}$ found that patients with knee OA treated with sham acupuncture by a practitioner, who expressed high expectations to the treatment, had better outcomes than those treated by a practitioner with a neutral position towards treatment effects. Although interaction between the patient and the practitioner is suggested as the most robust component of context effect, behaviour, communication and interaction between patient and practitioner are difficult to change and may be hard to reproduce. An advantage in exploiting the potential context effect from the physical environment is that the components of the environment can be thoroughly described and more easily implemented or changed in existing exercise environments.

There are some limitations to the study design that must be acknowledged. The multifactorial concept of context effects questions whether the physical environment can be isolated and studied alone. Several actions are taken to isolate the physical environment as the only difference between groups in this trial. The exercise programme is standardised and delivered in a group fashion by the same instructors, and all instructors have supervised in both physical environments. Consequently, treatment characteristics are similar between the intervention groups. Participants' characteristics, known and unknown, should be equally distributed between groups as a result of the randomisation process. Any specific characteristics that may originate from the instructor or from instructor-participant interaction should also be comparable between groups, as instructors supervise in both rooms.

Additionally, the nested qualitative study is aimed at investigating how the physical environment may affect the behaviour of the participants or instructors or the interaction between them. The study will elucidate these issues and help explain the process of how a standard and enhanced physical environment affects participants and instructors.

This study is designed to investigate the significance of the physical environment for the effects of exercise therapy and rehabilitation. The design of the study is novel and the results will provide knowledge on the significance of creating an optimal context for exercise therapy. Further studies investigating context effects of treatment are warranted to further enhance treatment effects. 
Acknowledgements The authors would like to thank Peter Møller Juhl, MSc $\mathrm{EE}, \mathrm{PhD}$, associate professor for assisting in measuring acoustic properties, and Anne Marie Rosager for invaluable help during the randomisation process.

Contributors LFS, JBT, RSU, PAD and EMR were all involved in the design of the study. All authors contributed tothe drafting of the manuscript or its revision. All authors read, commented and approved the manuscripts for publication. LFS is the trial manager and is responsible for coordinating and conducting the study. LFS, JBT and EMR comprise the steering committee for the study. LFS recruits, screens and conducts all baseline and follow-up testing, and monitors the data collection process during the trial, ensuring high completion rates for email-based surveys, objectively obtained outcomes and responses to reports of adverse events. Data analysis will be performed by a third party not related to the study.

Funding The study is supported by The Swedish Research Council (20064129) and the Faculty of Health at University of Southern Denmark for funding LFS's salary, and the Danish Rheumatism Association for supporting the study (grant number R114-A2632; May 2013).

\section{Competing interests None.}

Ethics approval The Regional Scientific Ethical Committee for Southern Denmark has approved the study (study ID: S-20130130). It is consistent with the Helsinki Declaration and registered with http://www.clinicaltrials.gov (ID: NCT02043613)

Provenance and peer review Not commissioned; peer reviewed for ethical and funding approval prior to submission.

Open Access This is an Open Access article distributed in accordance with the Creative Commons Attribution Non Commercial (CC BY-NC 4.0) license, which permits others to distribute, remix, adapt, build upon this work noncommercially, and license their derivative works on different terms, provided the original work is properly cited and the use is non-commercial. See: http:// creativecommons.org/licenses/by-nc/4.0/

\section{REFERENCES}

1. Ulrich R. View through a window may influence recovery from surgery. Science 1984;224:420-1.

2. Ulrich $\mathrm{R}$, Simons RF, Losito BD, et al. Stress recovery during exposure to natural and urban environments. J Environ Psychol 1991;11:201-30.

3. Parish JT, Berry LL, Lam SY. The effect of the servicescape on service workers. J Serv Res Us 2008;10:220-38.

4. Malenbaum S, Keefe FJ, Williams AC, et al. Pain in its environmental context: implications for designing environments to enhance pain control. Pain 2008;134:241-4.

5. Kweon BS, Ulrich RS, Walker VD, et al. Anger and stress-the role of landscape posters in an office setting. Environ Behav 2008;40:355-81.

6. Fransen M, McConnell S, Bell M. Therapeutic exercise for people with osteoarthritis of the hip or knee. A systematic review. J Rheumatol 2002;29:1738-46.

7. Fransen M, McConnell S. Land-based exercise for osteoarthritis of the knee: a metaanalysis of randomized controlled trials. $J$ Rheumatol 2009;36:1109-17.

8. Di Blasi Z, Harkness E, Ernst E, et al. Influence of context effects on health outcomes: a systematic review. Lancet 2001;357:757-62.

9. Miller FG, Kaptchuk TJ. The power of context: reconceptualizing the placebo effect. J R Soc Med 2008;101:222-5.

10. Koshi EB, Short CA. Placebo theory and its implications for research and clinical practice: a review of the recent literature. Pain Pract 2007;7:4-20.

11. Kaptchuk TJ. The placebo effect in alternative medicine: can the performance of a healing ritual have clinical significance? Ann Intern Med 2002;136:817-25.

12. Beecher HK. The powerful placebo. JAMA 1955;159:1602-6.

13. Miller FG, Rosenstein DL. The nature and power of the placebo effect. J Clin Epidemiol 2006;59:331-5.

14. Hrobjartsson A. The uncontrollable placebo effect. Eur J Clin Pharmacol 1996;50:345-8

15. Hrobjartsson A, Gotzsche PC. Is the placebo powerless? An analysis of clinical trials comparing placebo with no treatment. N Engl J Med 2001;344:1594-602.
16. Barrett B, Muller D, Rakel D, et al. Placebo, meaning, and health. Perspect Biol Med 2006;49:178-98.

17. Breidert M, Hofbauer K. Placebo: misunderstandings and prejudices Dtsch Arzteblatt Int 2009;106:751-5.

18. Margo CE. The placebo effect. Surv Ophthalmol 1999;44:31-44

19. Grunbaum A. The placebo concept. Behav Res Ther 1981;19:157-67.

20. Doherty M, Dieppe P. The "placebo" response in osteoarthritis and its implications for clinical practice. Osteoarthritis Cartilage 2009;17:1255-62.

21. Paterson C, Dieppe P. Characteristic and incidental (placebo) effects in complex interventions such as acupuncture. BMJ 2005;330:1202-5.

22. Dellmann $\mathrm{T}$, Lushington $\mathrm{K}$. How can complementary medicine practitioners enhance non-specific effects? J Aust Tradit Med Soc 2008;14:13-17.

23. Dieppe $\mathrm{P}$, Doherty M. Contextualizing osteoarthritis care and the reasons for the gap between evidence and practice. Clin Geriatr Med 2010;26:419-31

24. Moerman DE, Jonas WB. Deconstructing the placebo effect and finding the meaning response. Ann Intern Med 2002;136:471-6.

25. Schulz KF, Altman DG, Moher D, et al. CONSORT 2010 Statement: updated guidelines for reporting parallel group randomised trials. BMC Med 2010;8:18-26.

26. Kuttruff H. Room acoustics. London: Spon Press, 2000.

27. Ulrich RS, Zimring C, Zhu XM, et al. A review of the research literature on evidence-based healthcare design. $H E R D$ 2008;1:61-125.

28. Shepley MM, Gerbi RP, Watson AE, et al. The impact of daylight and views on ICU patients and staff. HERD 2012;5:46-60.

29. Walch JM, Rabin BS, Day R, et al. The effect of sunlight on postoperative analgesic medication use: a prospective study of patients undergoing spinal surgery. Psychosom Med 2005;67:156-63.

30. Ulrich RS. Human responses to vegetation and landscapes. Landscape Urban Plann 1986;13:29-44.

31. Ulrich RS. Natural versus urban scenes-some psychophysiological effects. Environ Behav 1981;13:523-56.

32. Tse MMY, NG JKF, Chung JWY, et al. The effect of visual stimuli on pain threshold and tolerance. J Clin Nurs 2002;11:462-9.

33. Diette GB, Lechtzin N, Haponik E, et al. Distraction therapy with nature sights and sounds reduces pain during flexible bronchoscopy: a complementary approach to routine analgesia. Chest 2003;123:941-8.

34. Ageberg E, Link A, Roos EM. Feasibility of neuromuscular training in patients with severe hip or knee OA: the individualized goal-based NEMEX-TJR training program. BMC Musculoskelet Disord 2010;11:126.

35. Zätterström R, Friden $\mathrm{T}$, Linstrand $\mathrm{A}$, et al. Early rehabilitation of acute anterior cruciate ligament injury - a randomized clinical trial. Scand J Med Sci Sports 1998(8):154-9.

36. Ageberg E, Zätterström R, Moritz U, et al. Influence of supervised and nonsupervised training on postural control after an acute anterior cruciate ligament rupture: a three-year longitudinal prospective study. J Orthop Sports Phys Ther 2001;31:632-44.

37. Ageberg E. Consequences of a ligament injury on neuromuscular function and relevance to rehabilitation-using the anterior cruciate ligament injured knee as model. J Electromyogr Kinesiol 2002;12:205-12.

38. Zätterström R, Friden T, Lindstrand A, et al. Muscle training in chronic anterior cruciate ligament insufficiency-a comparative study. Scand J Rehabil Med 1992;24:91-7.

39. Roos EM, Dahlberg L. Positive effects of moderate exercise on glycosaminoglycan content in knee cartilage: a four-month, randomized, controlled trial in patients at risk of osteoarthritis. Arthritis Rheum 2005;52:3507-14.

40. Ericsson YB, Dahlberg LE, Roos EM. Effects of functional exercise training on performance and muscle strength after meniscectomy: a randomized trial. Scand J Med Sci Sports 2009;19:156-65.

41. Villadsen A, Overgaard S, Holsgaard-Larsen A, et al. Postoperative effects of neuromuscular exercise prior to hip or knee arthroplasty: a randomised controlled trial. Ann Rheum Dis 2014;73:1130-7.

42. Kamper SJ, Maher CG, Mackay G. Global rating of change scales: a review of strengths and weaknesses and considerations for design. J Man Manip Ther 2009;17:163-70.

43. Guyatt $\mathrm{GH}$, Norman GR, Juniper EF, et al. A critical look at transition ratings. J Clin Epidemiol 2002;55:900-8.

44. Kaptchuk TJ, Kelley JM, Conboy LA, et al. Components of placebo effect: randomised controlled trial in patients with irritable bowel syndrome. BMJ 2008;336:999-1003. 
45. Roos E, Lohmander S. The knee injury and osteoarthritis outcome score (KOOS) — from joint injury to osteoarthritis. Health Qual Life Outcomes 2003;1:64-71.

46. Klassbo M, Larsson E, Mannevik E. Hip disability and osteoarthritis outcome score. An extension of the Western Ontario and McMaster Universities Osteoarthritis Index. Scand J Rheumatol 2003;32:46-51.

47. Roos E, Roos H, Lohmander S, et al. Knee injury and osteoarthritis outcome score (KOOS) - development of a self-administered outcome measure. J Orthop Sports Phys Ther 1998;78:88-96.

48. Roos EM, Toksvig-Larsen S. Knee injury and Osteoarthritis Outcome Score (KOOS) - validation and comparison to the WOMAC in total knee replacement. Health Qual Life Outcomes 2003;1:17.

49. Roos EM, Roos HP, Ekdahl C, et al. Knee injury and Osteoarthritis Outcome Score (KOOS) - validation of a Swedish version. Scand $J$ Med Sci Sports 1998;8:439-48.

50. Nilsdotter AK, Lohmander LS, Klassbo M, et al. Hip disability and osteoarthritis outcome score (HOOS) - validity and responsiveness in total hip replacement. BMC Musculoskelet Disord 2003;4:10.

51. Mchorney CA, Ware JE, Raczek AE. The Mos 36-Item Short-Form Health Survey (Sf-36) .2. Psychometric and clinical-tests of validity in measuring physical and mental-health constructs. Med Care 1993;31:247-63.

52. Mchorney CA, Ware JE, Lu JFR, et al. The Mos 36-Item Short-Form Health Survey (Sf-36) .3. Tests of data quality, scaling assumptions, and reliability across diverse patient groups. Med Care 1994;32:40-66.

53. Ware JE, Sherbourne CD. The Mos 36-Item Short-Form Health Survey (Sf-36) .1. Conceptual-framework and item selection. Med Care 1992;30:473-83.

54. Bandura A. Self-efficacy-toward a unifying theory of behavioral change. Psychol Rev 1977;84:191-215.

55. Lorig K, Chastain RL, Ung E, et al. Development and evaluation of a scale to measure perceived self-efficacy in people with arthritis. Arthritis Rheum 1989;32:37-44.

56. Skou ST, Odgaard A, Rasmussen JO, et al. Group education and exercise is feasible in knee and hip osteoarthritis. Dan Med J 2012;59:A4554

57. Brady TJ. Measures of self-efficacy: Arthritis Self-Efficacy Scale (ASES), Arthritis Self-Efficacy Scale-8 Item (ASES-8), Children's Arthritis Self-Efficacy Scale (CASE), Chronic Disease Self-Efficacy Scale (CDSES), Parent's Arthritis Self-Efficacy Scale (PASE), and Rheumatoid Arthritis Self-Efficacy Scale (RASE). Arthritis Care Res (Hoboken) 2011;63(Suppl 11):S473-85.

58. Tubach F, Ravaud P, Baron G, et al. Evaluation of clinically relevant states in patient reported outcomes in knee and hip osteoarthritis: the patient acceptable symptom state. Ann Rheum Dis 2005;64:34-7.

59. Lesage FX, Berjot S. Validity of occupational stress assessment using a visual analogue scale. Occup Med (Lond) 2011;61:434-6.

60. Astrand PO, Ryhming I. A nomogram for calculation of aerobic capacity (physical fitness) from pulse rate during sub-maximal work. J Appl Physiol 1954;7:218-21.

61. Thorborg K, Bandholm T, Holmich P. Hip- and knee-strength assessments using a hand-held dynamometer with external belt-fixation are inter-tester reliable. Knee Surg Sports Traumatol Arthrosc 2013;21:550-5.

62. Ageberg E, Bennell KL, Hunt MA, et al. Validity and inter-rater reliability of medio-lateral knee motion observed during a single-limb mini squat. BMC Musculoskelet Disord 2010;11:265-72.

63. Bremander AB, Dahl LL, Roos EM. Validity and reliability of functional performance tests in meniscectomized patients with or without knee osteoarthritis. Scand J Med Sci Sports 2007;17:120-7.

64. Thorlund JB, Aagaard P, Roos EM. Thigh muscle strength, functional capacity, and self-reported function in patients at high risk of knee osteoarthritis compared with controls. Arthritis Care Res (Hoboken) 2010;62:1244-51.
65. Dobson F, Hinman RS, Hall M, et al. Measurement properties of performance-based measures to assess physical function in hip and knee osteoarthritis: a systematic review. Osteoarthritis Cartilage 2012;20:1548-62.

66. Dobson F, Hinman RS, Roos EM, et al. OARSI recommended performance-based tests to assess physical function in people diagnosed with hip or knee osteoarthritis. Osteoarthritis Cartilage 2013;21:1042-52.

67. Wright AA, Cook CE, Baxter GD, et al. A comparison of 3 methodological approaches to defining major clinically important improvement of 4 performance measures in patients with hip osteoarthritis. J Orthop Sports Phys Ther 2011;41:319-27.

68. Gill S, McBurney $\mathrm{H}$. Reliability of performance-based measures in people awaiting joint replacement surgery of the hip or knee. Physiother Res Int 2008;13:141-52.

69. Tsai CY, Wang MC, Liao WT, et al. Hospital outpatient perceptions of the physical environment of waiting areas: the role of patient characteristics on atmospherics in one academic medical center. BMC Health Serv Res 2007;7:198-206.

70. Jarvinen TLN, Sihvonen R, Bhandari M, et al. Blinded interpretation of study results can feasibly and effectively diminish interpretation bias. J Clin Epidemiol 2014;67:769-72.

71. Davis BE. Rooftop hospital gardens for physical therapy: a post-cccupancy evaluation. HERD 2011;4:14-43.

72. Hrobjartsson A, Gotzsche PC. Placebo treatment versus no treatment. Cochrane Database Syst Rev 2003(1):CD003974.

73. Hrobjartsson A, Gotzsche PC. Is the placebo powerless? Update of a systematic review with 52 new randomized trials comparing placebo with no treatment. J Intern Med 2004;256:91-100.

74. Thompson WG. Placebos: a review of the placebo response. Am J Gastroenterol 2000;95:1637-43.

75. Di Blasi Z, Kleijnen J. Context effects. Powerful therapies or methodological bias? Eval Health Prof 2003;26:166-79.

76. Lang EV, Hatsiopoulou $\mathrm{O}$, Koch $\mathrm{T}$, et al. Can words hurt? Patient-provider interactions during invasive procedures. Pain 2005;114:303-9.

77. Benedetti $F$, Amanzio M. The placebo response: how words and rituals change the patient's brain. Patient Educ Couns 2011;84:413-19.

78. Bensing JM, Verheul W. The silent healer: the role of communication in placebo effects. Patient Educ Couns 2010;80:293-9.

79. Essers G, Kramer A, Andriesse B, et al. Context factors in general practitioner-patient encounters and their impact on assessing communication skills-an exploratory study. BMC Fam Pract 2013;14:65-72

80. Griffin SJ, Kinmonth AL, Veltmn MWM, et al. Effect on health-related outcomes of interventions to alter the interaction between patients and practitioners: a systematic review of trials. Ann Fam Med 2004;2:595-608.

81. Lonsdale C, Hall AM, Williams GC, et al. Communication style and exercise compliance in physiotherapy (CONNECT): a cluster randomized controlled trial to test a theory-based intervention to increase chronic low back pain patients' adherence to physiotherapists' recommendations: study rationale, design, and methods. BMC Musculoskelet Disord 2012;13:104.

82. Neumann M, Edelhauser F, Kreps GL, et al. Can patient-provide interaction increase the effectiveness of medical treatment or even substitute it?-an exploration on why and how to study the specific effect of the provider. Patient Educ Couns 2010;80:307-14.

83. Suarez-Almazor ME, Looney $\mathrm{C}$, Liu Y, et al. A randomized controlled trial of acupuncture for osteoarthritis of the knee: effects of patient-provider communication. Arthritis Care Res 2010;62:1229-36.

84. Teutsch C. Patient-doctor communication. Med Clin North Am 2003;87:1115-45.

85. Thomas K. General practice consultations-is there any point in being positive? BMJ 1987;294:1200-2. 